(C) 2022, The Authors. Published by Elsevier Inc. and Fass Inc. on behalf of the American Dairy Science Association ${ }^{\circledR}$. This is an open access article under the CC BY license (http://creativecommons.org/licenses/by/4.0/).

\title{
Graduate Student Literature Review: Considerations for nutritional grouping in dairy farms*
}

\author{
Jorge A. Barrientos-Blanco, $† \odot$ Heather White, $\odot$ Randy D. Shaver, and Victor E. Cabrerał $\odot$ \\ Department of Animal and Dairy Sciences, University of Wisconsin-Madison, Madison 53706
}

\begin{abstract}
Each cow in a group has different nutritional requirements even if the group is formed by cows of similar age, number of lactations, and lactation stage. Common dairy farm management setup does not support formulating a diet that accurately matches individual nutritional requirements for each cow; therefore, a proportion of cows in the group will be overfed and another proportion underfed. Overfeeding and underfeeding cows increases the risk of metabolic diseases, decreases milk production, and increases nutrient waste. Consequently, profitability of dairy farms and the environment are negatively affected. Nutritional grouping is a management strategy that aims to allocate lactating cows homogeneously according to their nutritional requirements. Groups of cows with more uniform nutritional requirements facilitates the formulation of more accurate diets for the group. Current availability of large data streams on dairy farms facilitates the design of algorithms to implement nutritional grouping. Our review summarizes important factors to consider when grouping cows, describes nutritional grouping approaches, and summarizes benefits of implementing nutritional grouping in dairy farms.
\end{abstract}

Key words: nutritional grouping, diet accuracy, nutritional group requirements, economic, environment

\section{INTRODUCTION}

One of the most critical challenges dairy farms face today is narrow profit margins (Bewley et al., 2015) due to the increasing price volatility and uncertainty of raw materials and milk. Additional challenges affecting dairy farm management include environmental regula-

Received August 11, 2021.

Accepted November 2, 2021.

*Submitted to the 2022 ADSA Foundation Graduate Student Literature Review Competition (Production, MS) on November 16, 2021.

†Corresponding author: jab924@cornell.edu

$\ddagger$ Advisor (vcabrera@wisc.edu) tions and consumers' demands for social sustainability and animal welfare (Spilke and Fahr, 2003; Bewley et al., 2015). Improving farm management efficiency can fulfill consumer's demands and environmental regulations while achieving farm profitability. Systematizing data collection and analysis is a potential strategy to enhance management efficiency and support improved decision-making processes (Bewley et al., 2015).

Precision dairy farming plays an essential role in improving dairy production sustainability (Chase, 2018). Precision dairy farming is defined as the actions of measuring and recording physiological, behavioral, and production performance from dairy cattle using automated systems to support better decision-making for improving production, economic, social, and environmental sustainability (Spilke and Fahr, 2003; Bewley, 2010). The adoption of new technologies to implement precision dairy farming generates constant real-time data streams (Liang et al., 2018). These large data streams include on-farm data from milking, feeding, reproduction, and weather condition records, along with off-farm records such as milk and feeds market prices. However, these data streams are individually collected and processed by different software (Liang et al., 2018). Integrating multiple data streams facilitates analysis of the global farm situation and generates an effective and efficient decision-making process on dairy farms (Cabrera et al., 2020; Liang et al., 2018). Collecting large real-time data allows the dairy farmer to monitor and identify significant physiological and behavioral abnormalities of the cows (Bewley et al., 2015). By detecting these abnormalities, dairy farmers have the chance to make strategic decisions that may result in higher productivity and profitability (Meijer and Peeters, 2010).

Improving dietary nutritional accuracy is part of the process to enhance precision dairy farming. Dietary nutritional accuracy is defined by Cerosaletti and Dewing (2008) as "the continual process of providing adequate, not excess, nutrients to the animal requirement and deriving a majority of nutrients from homegrown feeds through the integration of feeding and forage management for the purpose of maintaining environmental and economic sustainability." Real-time monitoring of 
weather conditions, feedstuff composition, mixed and delivered TMR, nutritional requirements, and DMI of lactating cows, and higher diet formulation frequency, improve nutritional accuracy of diets, productivity, and generate economic benefits (White and Capper, 2014).

White and Capper (2014) studied the interaction between climate and diet formulation frequency. They reported economic benefits when diets were formulated more frequently, considering changes in cow's energy requirements related to varying climate conditions. When diets are formulated every week, returns over costs may increase by $\$ 25,000 /$ yr for a 300 -cow operation (White and Capper, 2014). Maltz et al. (2013) performed a study on feeding 58 cows through the early and midlactation stages (from 1-19 wk) with a single control

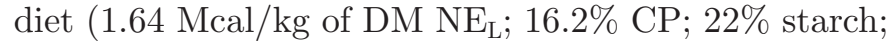
and $19 \% \mathrm{NDF}$ ) and a treatment precision diet. The precision diet consisted in adjusting the dietary $\mathrm{NE}_{\mathrm{L}}$ every week to achieve a calculated positive energy balance of $5 \mathrm{Mcal} / \mathrm{d}$ (dietary $\mathrm{NE}_{\mathrm{L}}$ ranged from 1.59-1.68 Mcal/kg of DM; CP 16.1-16.2\%, starch 18-26\%; and forage NDF 16-22\%). Results showed improvement in milk yield when diets matched individual cows' requirements over the lactation curve. Cows of the treatment group consumed $0.86 \mathrm{~kg}$ more concentrate per day and produced $3.3 \mathrm{~kg} / \mathrm{d}$ more milk, $3.2 \mathrm{~kg} / \mathrm{d}$ more FCM, and $2.8 \mathrm{~kg} / \mathrm{d}$ more ECM per cow than the cows of the control group.

Improvement in nutritional accuracy of diets can also be accomplished through cow grouping management (Kalantari et al., 2016; Bach et al., 2020; BarrientosBlanco et al., 2020). This concept is known as nutritional grouping (NG) and consists of grouping cows with similar nutritional requirements and providing an adjusted diet to each group (Cabrera et al., 2012). Nutritional grouping strategy facilitates improved allocation of nutrients due to decreased variance of nutritional requirements within each group (Cabrera et al., 2012; Kalantari et al., 2016; Wu et al., 2019; Barrientos-Blanco et al., 2020). As a result, dietary nutritional accuracy increases due to improving the match of diet to cow's nutritional requirements (Grant and Albright, 2001; Barrientos-Blanco et al., 2020). The objective of this literature review was to better understand the mathematical tools used to simulate NG and the benefits of implementing NG in dairy farms. This literature review focuses on important factors to be considered when grouping cows, developed methods for grouping cows by nutritional requirements, and the benefits of NG in milk production, profitability, and the environment.

\section{GROUPING FACTORS AND FEEDING MANAGEMENT}

Grouping management is an important aspect to consider for enhancing cow productivity, health, and profitability in farms with freestall barns. Grouping management affects the feeding behavior of dairy cows, which consequently improves milk production and economics of the farm (Sniffen, 1991). When grouping cows, it is important to consider factors such as DIM, age, lactation, and cows' social interaction and behavior, group size, the number of groups, bunk space, and facility design (Grant and Albright, 2001).

The essential factors to be considered for grouping cows are social interaction, body size and condition, age, DIM, stocking density per pen, stocking density at milking parlor's holding area, feed bunk space, the number of lying spaces, stalls design, and environmental conditions of the barn. Batchelder (2000) performed a study comparing the effect of headgates versus no headgates and 0 or $30 \%$ overcrowding of freestalls and bunk space. Results showed that cows decreased 3 to $6 \%$ DMI when cows are overcrowded at $30 \%$ in headgate (1.3 cows per headgate) pens (Table 1 ). Immediately after milking, 45 to $66 \%$ of nonovercrowded cows $(0 \%$ or 1 cow per headgate) in headgate pens ate, whereas only 28 to $30 \%$ of overcrowded cows (30\% or 1.3 cows per headgate) in headgate and pens ate. For the nonovercrowded group, 32 to $43 \%$ of cows ate at feeding time, whereas for the overcrowded group, only 21 to $27 \%$ of cows ate at feeding time. Also, in an observation period of $24 \mathrm{~h}$, on average, $28 \%$ of cows in the overcrowded groups were found ruminating, whereas 37\% of cows in nonovercrowded groups were ruminating. In contrast to the above findings, Bolinger et al. (1997) reported that headlocks do not affect daily DMI. They found that, after restrained in headlocks, cows spent more time laying down and less time eating, and they are more aggressive, although their DMI is not affected.

Table 1. Effects of cow maturity and pen stocking density on DMI

\begin{tabular}{lc}
\hline Factor & DMI range change \\
\hline Overcrowding at 30\% (1.3 cows per stall and headgate), \% & -3 to -6 \\
Effect in DMI when multiparous and primiparous cows are in separated groups, & +2.4 \\
$\mathrm{~kg} / \mathrm{d}$ & $1.5-2.2$ \\
Maximum DMI rate increase in multiparous cows, $\mathrm{kg} / \mathrm{d}$ & $1.2-1.6$ \\
Maximum DMI rate increase in primiparous cows, $\mathrm{kg} / \mathrm{d}$ & \\
\hline
\end{tabular}


Days in milk and age of cows are relevant factors to be considered on grouping cows (Grant and Albright, 2001). Kertz et al. (1991) showed that multiparous cows in the first $5 \mathrm{wk}$ of lactation have the fastest rate of increase in DMI, around 1.5 to $2.2 \mathrm{~kg}$ of DM/wk (Table 1). The rate of increase in DMI is $15 \%$ greater for multiparous cows than for primiparous cows (Kertz et al., 1991). Hierarchical dominance is observed in cow groups, primarily at feed bunks (Grant and Albright, 1995). It is correlated with cows' age, body size, and seniority of the group (Dickson et al., 1970). Primiparous cows are smaller and have lower hierarchical dominance in comparison to mature cows (Grant and Albright, 1995). The DMI of primiparous cows is negatively affected when they are in a group with multiparous cows when the feed quantity or bunk space are constrained (Grant and Albright, 2001). Therefore, a separate group assigned only for primiparous cows improves their DMI by $2.4 \mathrm{~kg} / \mathrm{d}$ (Table 1) and milk production by $207 \mathrm{~kg}$ in $130 \mathrm{~d}$ (Grant and Albright, 2001).

Competition for feed, water, and other resources, and herd health are factors that influence DMI. Cows that experience extreme environmental and social changes during the transition period are more susceptible to metabolic disorders and abnormal feeding behavior. Grouping transition cows separate from later lactation cows is recommended to facilitate their adaptation to the postpartum environment (Grant and Albright, 1995). Offering unlimited feed does not remove feeding competition but could avoid decreased DMI (Olofsson, 1999). It is recommended to have between 0.61 and $0.76 \mathrm{~m}$ of bunk space per cow with unlimited access to feed during the day (Grant and Albright, 2001).

Several studies have shown that shifts of cows between groups disrupt group hierarchy and may affect the DMI and milk productivity of the new cows in the group (i.e., Smith et al., 1978). However, the dominance hierarchy among the group is reestablished between 3 and $7 \mathrm{~d}$ after moving (Grant and Albright, 2001). Zwald and Shaver (2012) measured the effect of pen change in daily milk yield during the first $10 \mathrm{~d}$ postmovement. Farm A consisted of a group of 152 cows that did not change pens and 154 that were moved. Farm B had 142 cows that did not move pens and 137 cows that moved. The results showed that moving cows to different groups does not cause a significant decrease in milk yield. In a trial of 100 cows managed with 3-grouping and 1-grouping management as control, Clark et al. (1977) found no significant difference in milk yield 5 $\mathrm{d}$ after cows were changed to a different group once a month. In contrast, Smith et al. (1978) measured the effect of 1 and 2-group management strategy in milk yield. Cows in the 1-group management strategy were fed with a TMR containing 56\% (as DM) corn silage and $44 \%$ of concentrate. Cows in the high production group of the 2-group management were fed with a ration of $56 \%$ corn silage and $44 \%$ concentrate, and cows in the low-production group were fed with a ration of $84 \%$ corn silage and $16 \%$ concentrate. The results showed that 2-grouping management decreases milk yield by $2 \mathrm{~kg} /$ cow per day in the first week after grouping the cows. Also, the decrease in milk yield persisted longer for multiparous cows than primiparous cows.

\section{NUTRITIONAL GROUPING}

\section{Nutritional Grouping Methods}

In a grouping simulation study, Williams and Oltenacu (1992) suggested that $\mathrm{NE}_{\mathrm{L}}$ and $\mathrm{CP}$ requirements per kilogram of DMI and per kilogram of NDF intake capacity are the most relevant factors for grouping cows. McGilliard et al. (1983) used a ranking cluster as a method for grouping cows according to their net energy $\left(\mathbf{N E} ; \mathrm{NE}_{\mathrm{L}}+\mathrm{NE}_{\mathrm{M}}\right.$ ) and $\mathrm{CP}$ requirements. The first step of this method is to standardize NE and CP concentration requirements $\left(u=0, \sigma^{2}=1\right)$. The values are normalized by subtracting the average NE and $\mathrm{CP}$ concentration requirements of the herd from the individual cow $\mathrm{NE}$ and $\mathrm{CP}$ requirement and dividing it by the standard deviation of the NE and CP concentration requirements. Then, the standardized values are ranked, and cows are grouped by percentile rank. With this method, the group sizes are equal over time and allow the farm manager to use one or multiple nutritional requirements as grouping variables (McGilliard et al., 1983). Barrientos-Blanco et al. (2020) used the same ranking-cluster method in a NG simulation study. However, the cows were first grouped according to their parity, stage of lactation (postpartum, early, peak, and late lactation), respective farm commercial conditions, and then grouped according to the $\mathrm{NE}_{\mathrm{L}}$ and MP requirements and milk yield.

Different than the ranking-cluster method, Cabrera et al. (2012) suggested an iterative searching of global maximum income over feed cost (IOFC) as a method to perform NG. This method allocates cows by nutrient requirements to a predetermined number of groups and size of those groups, then maximizes the global IOFC of the herd. The maximum IOFC is calculated using Equation1:

$$
\operatorname{Max}(\operatorname{IOFC})=\Sigma G_{\text {group }}=\left(\operatorname{IOF} C_{\text {group }}\right)
$$

where $I O F C_{\text {group }}=\left(\right.$ Milk $\left._{\text {group }}\right)($ Milk Price $)-($ Feed Cost $\left._{\text {group }}\right)$, FeedCost $_{\text {group }}=\left[83 \%\right.$ tile $C P_{\text {group }}($ CPPrice $\left.)\right]+$ [83\% tile $N E_{\text {group }}$ (NEPrice)], IOFC = income over feed cost, and $G=$ total number of groups $(2,3$, or 4$)$. 
Cabrera et al. (2012) calculated the CP and NE group requirement using the 83rd percentile lead factor suggested by Stallings and McGilliard (1984) to formulate the diet of each group and estimate the feeding cost.

Following the iterative search of the global maximum IOFC method, Wu et al. (2019) suggested the OptiGroup as a method to implement NG. OptiGroup consists of finding the cows group arrangement that maximizes the global IOFC of the herd using a mixedinteger nonlinear programming optimization algorithm. The objective equation of the model is maximizing IOFC as follows in Equation [2]:

$$
\begin{aligned}
& \operatorname{Max}(\operatorname{IOFC})=\sum_{i=1}^{n} \\
& \left(P_{\text {milk }} \sum_{i=1}^{N_{j}} g_{j i} M Y_{i}-C_{N E} \sum_{i=1}^{N_{j}} g_{j i} D M I_{i} N E_{\text {diet }, j}-C_{C P} \sum_{i=1}^{N_{j}} g_{j i} D M I_{i} C P_{\text {diet }, j}\right),
\end{aligned}
$$

subject to $\sum_{i=1}^{N} g_{j i}=1$; every cow belongs to one group $g_{j i} \in\{0,1\}$.

$N_{1}=N_{2}$ for 2 groups or $N_{1}=N_{2}=N_{3}$ for 3 groups,

$$
\begin{aligned}
& N E_{\text {diet }, 1}=N E_{\text {diet }, 2} \text { for } 2 \text { groups or } \\
& N E_{\text {diet }, 1}=N E_{\text {diet }, 2}=N E_{\text {diet }, 3} \text { for } 3 \text { groups, } \\
& C P_{\text {diet }, 1}=C P_{\text {diet }, 2} \text { for } 2 \text { groups or } \\
& C P_{\text {diet }, 1}=C P_{\text {diet }, 2}=C P_{\text {diet }, 3} \text { for } 3 \text { groups, }
\end{aligned}
$$

where $j=$ group number; $n=$ number of groups (2 or $3) ; i=$ cow number; $N_{j}=$ number of cows in group $j$; $P_{\text {milk }}=$ price of the milk; $g_{j i}=$ cow $i$ in group $j ; M Y_{1}=$ milk yield of cow $i ; C_{N E}=$ cost of NE nutrient per unit; $D M I_{i}=$ estimated DMI of cow $i ; N E_{\text {diet }, j}=\mathrm{NE}$ density in the diet of group $j ; C_{C P}=$ cost of crude protein nutrient per unit; $C P_{\text {diet }, j}=$ crude protein percentage in the diet of group $j$.

A different approach for implementing NG strategy is using K-means analysis. Forgey (1965) developed the K-means clustering algorithm; an unsupervised machine learning algorithm used to find subgroups in an observation data set. This clustering algorithm is capable of grouping cows according to NEL and MP requirements and any other nutritional requirement parameters at the same time. K-means method identifies which observations are similar and categorizes them into a pre-specified number of subgroups. The algorithm looks for observations with minimum variability within clusters and maximum dissimilarity between clusters.
The variability is measured as the distance between observations or as correlation-base distance. There are Euclidean and Manhattan methods that measure the distance between observations and Pearson, Kendall, and Spearman methods that measure the correlationbased distances. The Euclidean method measures the distance between 2 vectors $\mathbf{x}$ and $\mathbf{y}$ of length $n$ :

$$
d_{\text {euc }}(\mathbf{x}, \mathbf{y})=\sqrt{\sum_{i=1}^{n}\left(\mathbf{x}_{i}-\mathbf{y}_{i}\right)^{2}} .
$$

Similarly, the Manhattan method measures the distance between 2 vectors $\mathbf{x}$ and $\mathbf{y}$ of length $n$ but uses

$$
d_{\text {man }}(\mathbf{x}, \mathbf{y})=\sum_{i=1}^{n}\left|\left(\mathbf{x}_{i}-\mathbf{y}_{i}\right)\right|
$$

Pearson method is done by

$$
d_{c o r}(\mathbf{x}, \mathbf{y})=1-\frac{\sum_{i=1}^{n}\left(\mathbf{x}_{i}-\overline{\mathbf{x}}\right)\left(\mathbf{y}_{i}-\overline{\mathbf{y}}\right)}{\sqrt{\sum_{i=1}^{n}\left(\mathbf{x}_{i}-\overline{\mathbf{x}}\right)^{2}} \sum_{i=1}^{n}\left(\mathbf{y}_{i}-\overline{\mathbf{y}}\right)^{2}},
$$

where $\mathbf{x}$ and $\mathbf{y}$ are the vectors with length $n$. The Spearman method uses the same equation as Pearson, but with ranked vectors:

$$
d_{c o r}(\mathbf{x}, \mathbf{y})=1-\frac{\sum_{i=1}^{n}\left(\mathbf{x}_{i}^{\prime}-\overline{\mathbf{x}}^{\prime}\right)\left(\mathbf{y}_{i}^{\prime}-\overline{\mathbf{y}}^{\prime}\right)}{\sqrt{\sum_{i=1}^{n}\left(\mathbf{x}_{i}^{\prime}-\overline{\mathbf{x}}^{\prime}\right)^{2}} \sum_{i=1}^{n}\left(\mathbf{y}_{i}^{\prime}-\overline{\mathbf{y}}^{\prime}\right)^{2}},
$$

where $\mathbf{x}_{i}^{\prime}=\operatorname{rank}\left(\mathbf{x}_{i}\right)$ and $\mathbf{y}_{i}^{\prime}=\operatorname{rank}\left(\mathbf{y}_{i}\right)$. Kendall method measures the correspondence between the ranking of $x$ and $y$ variables following

$$
d_{\text {kend }}(x, y)=1-\frac{n_{c}-n_{d}}{\frac{1}{2} n(n-1)},
$$

where $n$ is the length of $x$ and $y, \frac{1}{2} n(n-1)$ is the total number of possible pairings of $x$ with $y$ observations, $n_{c}$ [concordant pairs (c)] are the numbers of $y_{i}$ that is larger than each $y_{i}$ and $n_{d}$ [discordant pairs (d)] are the numbers of $y_{i}$ that are lower than each $y_{i}$. The most common method to measure distance is Euclidean; however, the method to be used depends on the type of data or purpose. K-means clustering is performed in 4 steps: (1) set the number of groups $(k),(2)$ calculate the means of each cluster, (3) assign the observations to the closest Euclidean distance mean of the cluster, and 
(4) calculate the mean of each cluster (center) iteratively repeating step 3 until the algorithm finds the minimum total variation between observations and the center of the cluster. The standard K-means algorithm (Hartigan-Wong algorithm) used in step 4 calculates the Euclidean distance to determine the total withincluster variation between the observations and the center of each cluster. The Hartigan-Wong algorithm is as follows:

$$
\sum_{k=1}^{k} W\left(C_{k}\right)=\sum_{k=1}^{k} \sum_{x_{i} \in C_{k}}\left(x_{i}-u_{k}\right)^{2},
$$

where $k$ is the number of groups; $x_{i}$ is the observation that belongs to the cluster $C_{k}$; and $u_{k}$ is the average values of the observations that belong to the cluster $C_{k}$. The final clusters have minimum variance between observations within the groups. The number of clusters $(k)$ is predetermined, and the number of observations may be dissimilar between clusters. However, Bach et al. (2020) clustered cows constraining the number of observation (cows) per group, which facilitates the implementation of NG using K-means in farms with predetermined number of cows per pen.

\section{Optimal Factors to Consider for Grouping Cows}

In a simulation grouping study, McGilliard et al. (1983) compared grouping by their percentage CP requirements and $\mathrm{NE}$ requirements per kilogram of expected DMI with grouping cows by daily milk yield, $\mathrm{FCM}$, and dairy merit $\left(\mathrm{FCM} / \mathrm{BW}^{0.75}\right)$. The analysis showed that using ranking-cluster method for NG resulted in a lower within-group variance (CP: $\sigma^{2}=2.14$ and NE: $\left.\sigma^{2}=0.0137\right)$ than grouping by milk yield (CP: $\sigma^{2}=2.84$ and NE: $\left.\sigma^{2}=0.0204\right)$, FCM $\left(\mathrm{CP}: \sigma^{2}=2.65\right.$ and NE: $\left.\sigma^{2}=0.0192\right)$, and dairy merit (CP: $\sigma^{2}=2.39$ and NE: $\left.\sigma^{2}=0.0177\right)$. Later, Kalantari et al. (2016) did a NG study using $\mathrm{NE}_{\mathrm{L}}$ and $\mathrm{MP}$, instead of $\mathrm{CP}$, as factors for grouping cows. The results showed that using both nutrients as grouping factors for 2 or $3 \mathrm{NG}$ minimized the nutritional requirements, DIM, and milk yield variability within the cow groups. Groups with lower nutritional requirement variance facilitated the formulation of more accurate diets that decreased the overfed and underfed number of cows, and improved productivity and profitability.

\section{Formulation of Diets for NG}

The lead factor is an important conversion factor to formulate an optimum diet for a group of cows (StPierre and Thraen, 1999). Lead factor is defined as the mean plus one standard deviation $($ mean $+1 \times S D)$ or 83rd percentile milk yield value of a group of lactating cows in Stallings and McGilliard (1984) and St-Pierre and Thraen (1999). The cow that has the closest milk yield to the lead factor is used as a reference to calculate cow's $\mathrm{CP}$ and NE requirement. Both nutrient requirements are calculated according to the cow $\mathrm{BW}$, milk yield, and milk components (protein, fat, lactose). Mean $+1 \times S D$ and 83rd percentile methods are sensitive to herd size, season, and milk performance (Stallings and McGilliard, 1984). According to Stallings and McGilliard (1984), 83rd percentile is the best method to calculate lead factor values for balancing dairy diets. Even though the 83rd percentile method does not yield the most economical diet, it does promote the increase of milk production, or minimizes the overfeeding of cows with low milk yields (Stallings and McGilliard, 1984). However, Bach et al. (2020) estimated that IOFC does not always increase when feeding cows to promote maximum milk yield or feed efficiency. In a simulation analysis, Bach et al. (2020) proposed to aggregate 228 cows in 3 groups (low, medium, and high production) and feed them with 3 different diets covering the requirements of $70 \%$ of the cows in each group. The weighted average IOFC of the 3 groups $(\$ 8.24 / \mathrm{d})$ was $\$ 0.78 / \mathrm{d}$ lower than the IOFC if each cow would be fed with an adjusted individual diet $(\$ 9.02 / \mathrm{d})$ but $\$ 0.20 /$ d higher than feeding all the cows with a singular diet $(\$ 8.04 / \mathrm{d})$. In other studies, optimal $\mathrm{NE}_{\mathrm{L}}$ and MP requirements per nutritional group were calculated using mean $+1 \times S D$ of the group's $\mathrm{NE}_{\mathrm{L}}$ and $\mathrm{MP}$ requirement distribution (Cabrera et al., 2012; Kalantari et al., 2016; Wu et al., 2019). With this optimal $\mathrm{NE}_{\mathrm{L}}$ and MP requirement per group, they calculated the diet's cost and the IOFC of each nutritional group. In a similar approach, St-Pierre and Thraen (1999) have suggested the use of differentiated lead factor per group, which depends on the number of groups. When cows are aggregated in 2 groups, 1.19 and 1.30 are the lead factors used to be multiplied by milk yield and calculate the $\mathrm{NE}_{\mathrm{L}}$ requirement for the lowest milk yield group 1 and highest milk yield group 2, respectively. When cows are aggregated in 3 groups, the lead factor are 1.15 for the lowest milk yield group 1, 1.21 for the medium milk yield group 2, and 1.29 for the highest milk yield group 3 . The lead factor multiplied by the milk yield to calculate the $\mathrm{CP}$ requirement per group of 3-grouping strategy are 1.11 for the lowest milk yield group 1, 1.17 for the medium milk yield group 2, and 1.24 for the highest milk yield group 3 . When cows are aggregated in 2 groups, the lead factor to calculate the CP requirement of each group are 1.13 and 1.25 for the lowest milk yield group 1 and the highest milk yield group 2, respectively. 
These lead factors from St-Pierre and Thraen (1999) are derived from economic optimization. They have a similar magnitude to the 83rd percentile method suggested by Stallings and McGilliard (1984). However, the lead factors from St-Pierre and Thraen (1999) are lower for the lowest milk production groups. For example, when aggregating cows in 3 groups, Stallings and McGilliard (1984) suggested a lead factor of 1.14 for group 1, 1.10 for group 2, and 1.21 for group 3 .

\section{Benefits of NG Management for Milk Production}

Nutritional grouping management yields groups of cows with less variable nutritional requirements (Kalantari et al., 2016; Wu et al., 2019; Barrientos-Blanco et al., 2020). This strategy facilitates a better allocation of diet nutrients across groups and, therefore, greater nutritional accuracy of diets (Cabrera and Kalantari, 2016; Kalantari et al., 2016; Barrientos-Blanco et al., 2020). Greater dietary nutritional accuracy decreases the proportion of underfed and overfed cows in the herd (Kalantari et al., 2016; Bach et al., 2020). Table 2, adapted from Kalantari et al. (2016), Wu et al. (2019), and Barrientos-Blanco et al. (2020) simulation studies, show the difference between the offered $\mathrm{NE}_{\mathrm{L}}$ (Mcal/ $\mathrm{kg}$ of DM), CP (\% of DM), RDP (\% of DM), and MP (g/ $\mathrm{kg}$ of DM) concentration in the diet for 1-, 2-, and 3-NG scenarios using ranking-cluster and OptiGroup methods. The supplied nutrients in the diet were higher in 1 group scenario than in the 2 and 3 group simulated scenarios. These higher difference in 1 group strategy is explained by the larger nutritional requirements variability within the group. Table 2 proves that increasing the number of nutritional groups decreases the nutritional requirement variability within groups. Therefore, it facilitates the formulation of diets, which better match the cow nutritional requirements. Also, Kalantari et al. (2016) NG simulation analysis showed that in the 1 group scenario, approximately $50 \%$ of the cows are underfed and the other $50 \%$ are overfed due to higher variability of nutritional requirements within the group. Using NG strategy, cows with low nutritional requirements get less dense and cheaper diets. In contrast, cows with high nutritional requirements get denser and more expensive diets (Bach, 2014; Kalantari et al., 2016; Barrientos-Blanco et al., 2020). Feeding multiple rations that better match nutritional requirements enhances the potential milk productivity of high production cows and decrease over-conditioning of cows with lower milk yield (Allen, 2009).

It can be speculated that better allocation of dietary nutrients using NG strategy can improve profitability by increasing milk yield and decreasing dietary cost. In a simulation study, Barrientos-Blanco et al. (2020)

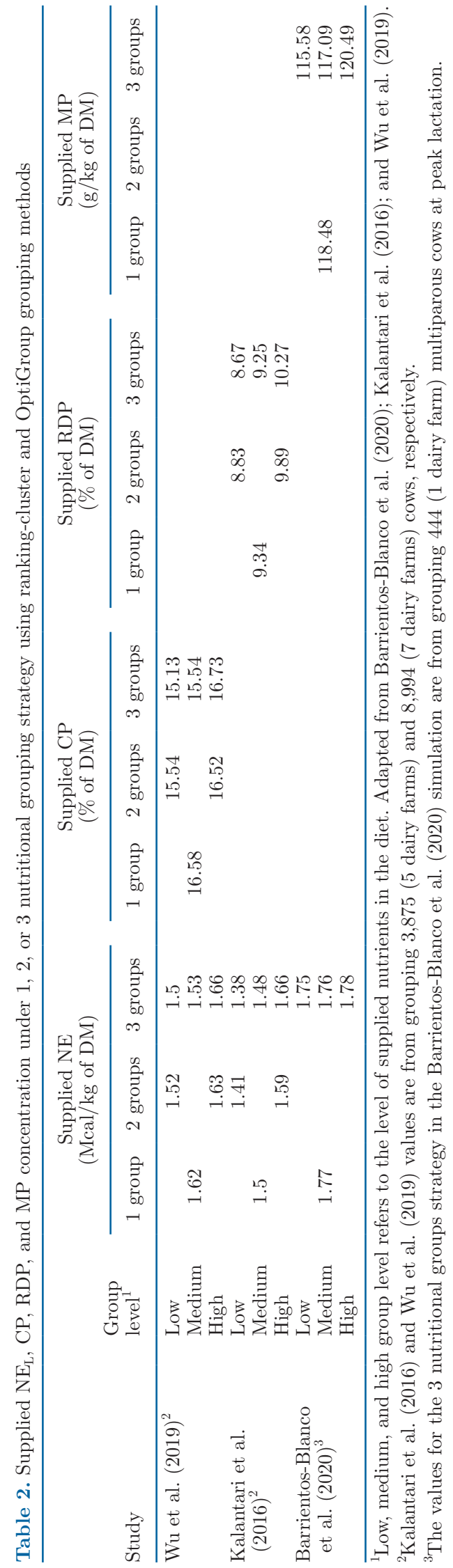


demonstrated that postpartum and early-lactation cows required the highest $\mathrm{MP}$ and $\mathrm{NE}_{\mathrm{L}}$ density diets, while late-lactation cows required the lowest MP and $\mathrm{NE}_{\mathrm{L}}$ density diets. In this simulation study, postpartum and early-lactation groups would receive denser diets formulated with higher concentrate:forage ratio than lower density diets proposed for the late-lactation cows. This allocation of nutrients resulted in lower dietary cost.

The milk production benefits from better nutrients allocation using NG strategy can be supported by the findings of Okine et al. (1997), Moorby et al. (2006), and Hernandez-Urdaneta et al. (1976) studies. Okine et al. (1997) reported 14\% higher FCM yield when latelactation (>200 DIM) cows were fed with 50:50 forage: concentrate ratio rather than 65:35 forage: concentrate ratio diet. In another study, feeding mid-lactation (90 \pm 33.6 DIM) cows with 80:20, 65:35, 50:50, and 35:65 forage:concentrate ratio diets, Moorby et al. (2006) reported a significant linear increase on milk yield $(P<$ $0.001)$ as the fermentability of the diets increased. The results showed up to almost $8 \mathrm{~kg} / \mathrm{cow}$ per day greater on milk yield when cows were fed with 35:65 rather than 80:20 forage:concentrate ratio diets. HernandezUrdaneta et al. (1976) reported that feeding earlylactation (4-28 DIM) cows a 40:60 forage:concentrate ratio diet contributed to an increase of $2.8 \mathrm{~kg} /$ cow per day milk yield compared with early-lactation cows fed with a 60:40 forage:concentrate ratio diet. The result of these studies suggest that cows in late lactation can consume higher forage diets than early and midlactation cows without compromising the milk yield at lower dietary cost.

\section{Economic Benefits of NG Management}

Grouping cows, according to their $\mathrm{CP}$ and NE requirements per kilogram of DM and NDF intake capacity, improves IOFC due to increased milk yield (Williams and Oltenacu, 1992). Williams and Oltenacu (1992) study showed that per cow and per year, IOFC for 3-nutritional groups management was $\$ 21(8,000$ $\mathrm{kg}$ of milk production at $305-\mathrm{d}), \$ 33(9,000 \mathrm{~kg}$ of milk production at $305-\mathrm{d})$, and $\$ 40(10,000 \mathrm{~kg}$ of milk production at 305-d) greater than 2-nutritional groups management. St-Pierre and Thraen (1999) reported that NG strategy decreased the variance of the nutritional requirements within the groups, which improved the allocation of nutrients and increased milk yield. As a result, the IOFC increased by $\$ 43.80 /$ cow per year when cows were aggregated in 2 nutritional groups and $\$ 76.65 /$ cow per year when cows were aggregated in 3 nutritional groups. Cabrera et al. (2012) performed a simulation NG study using a ranking and iterative method for maximizing global IOFC of the herd. Using a data set from 30 Wisconsin herds, they showed that 3 nutritional groups increased IOFC by $\$ 396 /$ cow per year. Kalantari et al. (2016) evaluated the economic effect of NG in 5 commercial dairy herds using a stochastic Monte Carlo simulator model. Using the data sets from the farms included in the study, the simulator scheduled the events that could happen to cows on each of their reproductive cycles. The aggregation of cows in nutritional groups was performed using the ranking and iterative method for maximum global IOFC of the groups suggested by Cabrera et al. (2012). In a first step, cows were categorized into 2 subgroups: obligated and optional. The obligated subgroup was assigned to dry and postpartum (<21 DIM) cows, which were subdivided into 2 nutritional groups. Dry cows were fed a constant NE of $1.28 \mathrm{Mcal} / \mathrm{kg}$ of DM and MP of $7 \mathrm{~g} / 100$ $\mathrm{g}$ of DM diet. Early cows were fed a constant $\mathrm{NE}_{\mathrm{L}}$ of 1.7 $\mathrm{Mcal} / \mathrm{kg}$ of DM diet and the provided MP was calculated based on the 83rd percentile of the MP requirement of the group. Optional subgroup was set for the cows with more than 21 DIM. This subgroup was used to evaluate the implementation of NG management. Cows from optional subgroup were aggregated into groups according to their NE and MP nutritional requirements once per month. The study showed that the gain of IOFC for 2 nutritional groups was $\$ 39 /$ cow per year, for 3 nutritional groups was $\$ 46 /$ cow per year, and for 4 nutritional groups was $\$ 47 /$ cow per year when diets were formulated to the mean $+1 \times S D$ of the groups' $\mathrm{MP}$ and average $\mathrm{NE}_{\mathrm{L}}$ requirements. Wu et al. (2019) performed a NG simulation study using a mixed-integer nonlinear programming optimization algorithm (OptiGroup). A database comprised of 7 Wisconsin dairy farms was used to simulate the implementation of NG and measure its economic impact. The study compared 1 nutritional group as control against 2 and 3 nutritional groups, contrasting the clustering method and the newly developed OptiGroup method. They found that the IOFC for 2-nutritional groups was $\$ 40 / \mathrm{cow}$ per year and for 3 nutritional groups was $\$ 59 /$ cow per year greater than 1-group strategy with the clustering method. Using OptiGroup method, the IOFC for 2-nutritional groups increased to $\$ 48 /$ cow per year and for 3 -nutritional groups to $\$ 71 /$ cow per year greater than the 1-group strategy. Barrientos-Blanco et al. (2020) performed a simulation study to estimate the economic impact of implementing NG strategy with ranking clustering method in a commercial Wisconsin dairy farm. In this study, the NG strategy was simulated taking into account the farm existing grouping protocol. The goal of including the farm grouping protocol was to minimize the labor cost related to implementing NG strategy and any investment in farm facilities. The NG 
simulation regrouped every week 14 pens of lactating cows $(\mathrm{n}=2,374 \pm 185)$ according to the current farm grouping criteria (stage of lactation and parity), $\mathrm{NE}_{\mathrm{L}}$ (Mcal $/ \mathrm{kg}$ of $\mathrm{DM})$ and $\mathrm{MP}(\mathrm{g} / \mathrm{kg}$ of $\mathrm{DM})$ predicted requirements and milk yield. Diets were reformulated to match the $\mathrm{NE}_{\mathrm{L}}$ and MP requirements of the NG using the farm diet formulation criteria and ingredients. Results showed a net return increase of $\$ 31 /$ cow per year from dietary cost saving using NG strategy. The results also demonstrated that using the NG algorithm removed the risk of overstocking or understocking cows in the groups by keeping constant the number of cows per pen and removing the risk of misclassifying cows to pens.

\section{Environmental Benefits of NG}

When the number of nutritional groups increases, the total percentage of captured $\mathrm{N}$ in milk increases, benefiting the environment (St-Pierre and Weiss, 2015; Kalantari et al., 2016). Less $\mathrm{N}$ is excreted as waste when low-production cows are fed a diet that better matches their nutritional requirements (Allen, 2009; Barrientos-Blanco et al., 2020). Kalantari et al. (2016) found that $\mathrm{N}$ efficiency increased by $2.7 \%$, on average, when cows are aggregated in 3 nutritional groups and fed with diets that supply one standard deviation over the average MP requirement of each nutritional group. Barrientos-Blanco et al. (2020) estimated a theoretical decrease of $15.14 \mathrm{~g} /$ cow per day in supplied dietary $\mathrm{N}$ when primiparous peak-lactation cows were aggregated in 3 nutritional groups, multiparous peak-lactation cows in 3 nutritional groups, and primiparous and multiparous late-lactation cows in 4 nutritional groups. This improvement in $\mathrm{N}$ efficiency was explained by a better match of MP supplied in the diet to the group's MP requirement (Kalantari et al., 2016; Barrientos-Blanco et al., 2020). St-Pierre and Thraen (1999) reported that N efficiency increased by $5.8 \%$ and $\mathrm{N}$ excretion decreased $3.7 \%$ when cows were grouped in 3 nutritional groups using the clustering method suggested by McGilliard et al. (1983). Decreasing $2 \%$ of CP concentration in diets for $120 \mathrm{~d}$ per lactation decreases $\mathrm{N}$ excretion by 9.07 $\mathrm{kg} /$ cow per year (Allen, 2009).

\section{CURRENT GROUPING MANAGEMENT ON DAIRY FARMS}

Grouping cows and feeding one diet for all the groups or feeding a diet for each group is a common practice in dairy farms. Contreras-Govea et al. (2015) surveyed farmers from Wisconsin and Michigan to quantify the percentage for dairy farms in those states that provide one or multiple diet formulas for lactating cows, and identify the criteria used for grouping cows and the drawbacks on adopting nutritional criteria for grouping management. According to Contreras-Govea et al. (2015), in Wisconsin and Michigan, 26 and $42.5 \%$ of dairy farms use a single diet for feeding the whole group of lactating cows, respectively. The survey also showed that the main criteria for grouping lactating cows are lactation category (first-lactation cows and mature cows) and stage of lactation (early cows and all other cows), whereas nutrition requirements are not commonly used for grouping cows. In both states, lactation category is the first, stage of lactation is the second, and milk production is the third most important factor used for grouping and feeding cows.

\section{FUTURE RESEARCH}

As previously discussed, multiple simulation studies have demonstrated productive, economic, and environmental benefits of NG strategies on dairy farms; however, research has not been performed on farms to validate the findings from these simulation studies. Indeed, there are no studies measuring milk production responses and profitability when lactating cows are grouped using a NG strategy versus current grouping practices. There are no studies that have compared the nitrogen levels in urine and milk using NG strategies. Additionally, applications that offer the NG option are scarce in the dairy industry. More applications that systematically collect, integrate, and implement NG strategies on dairy farms are needed. The differences between herd management practices among dairy farms is a factor that must be considered when implementing a NG strategy. On-farm research is required to evaluate strategies on how to implement a NG application considering herd management practices.

\section{CONCLUSIONS}

Several studies support that NG strategy increases nutritional accuracy of diets, and therefore, improve nutritional precision dairy farming. Increasing diets' nutritional accuracy prevents nutrient loss, decrease diet cost, and potentially increase milk yield. Cows age and body size, their social interaction, barn design, and feed availability are essential factors to consider when grouping cows. A NG strategy can be implemented using ranking clusters, iterative search of global maximum IOFC, OptiGroup, and K-means analysis. The algorithm to be used depends on the farm's data and facilities, goals, and grouping management practices. Nitrogen and other nutrients excretion as waste can be reduced by implementing a NG strategy due to better allocation of diet nutrients. Decreased nutrient losses 
and greater nutritional accuracy of the dietary groups can improve IOFC due to diet cost savings and potential milk yield increase. Even though grouping is a common practice in dairy farms, dairy farmers rarely implement NG strategy due to the potential implementation complexity and potential loss on milk productivity due to the increase cow's movements between pens over lactating time. Current management record systems, advanced computer systems and algorithms provide real-time large data streams that can be used for more efficient and accurate cow grouping management. Our literature review reveals that further field research is needed to measure and quantify the effect of using NG strategy on milk production, economics, and environment.

\section{ACKNOWLEDGMENTS}

This project was supported by the University of Wisconsin-Madison UW2020 initiative to project entitled A Virtual Dairy Farm Brain: The Next Big Leap in Dairy Farm Management Applying Artificial Intelligence; the USDA-NIFA-FACT grant 2019-68017-29935 to project entitled: Developing a Dairy Brain: The Next Big Leap in Dairy Farm Management Using Coordinated Data Ecosystems; and Hatch Project no. WIS01849 to V. E. Cabrera and R. D. Shaver. The authors also thank Liliana Fadul-Pacheco (Department of Dairy Science, University of Wisconsin, Madison) for her contribution to this work. The authors have not stated any conflicts of interest.

\section{REFERENCES}

Allen, M. S. 2009. Grouping to increase milk yield and decrease feed costs. Pages 61-65 in Proc. Tri-State Dairy Nutr. Conf., Ft. Wayne, IN. The Ohio State University.

Bach, A. 2014. Precision feeding to increase efficiency for milk production. WCDS Adv. Dairy Technol. 26:177-189.

Bach, A., M. Terré, and M. Vidal. 2020. Symposium review: Decomposing efficiency of milk production and maximizing profit. J. Dairy Sci. 103:5709-5725. https://doi.org/10.3168/jds.2019-17304.

Barrientos-Blanco, J. A., H. White, R. D. Shaver, and V. E. Cabrera. 2020. Improving nutritional accuracy and economics through a multiple ration-grouping strategy. J. Dairy Sci. 103:3774-3785. https://doi.org/10.3168/jds.2019-17608.

Batchelder, T. 2000. The impact of head gates and overcrowding on production and behavior patterns of lactating dairy cows. Pages 325-330 in Dairy Housing and Equipment Systems: Managing and Planning for Profitability. Natural Resource, Agriculture, and Engineering Service Publ.

Bewley, J. 2010. Precision dairy farming: advanced analysis solutions for future profitability. Pages $2-5$ in Proc. First North American Conference on Precision Dairy Management. Progressive Dairy Operators.

Bewley, J. M., R. A. Russell, K. A. Dolecheck, and M. R. Borchers. 2015. Precision dairy monitoring: what have we learned? Pages 13-24 in Precision Livestock Farming Applications. Wageningen Academic Publishers.
Bolinger, D. J., J. L. Albright, J. Morrow-Tesch, S. J. Kenyon, and M. D. Cunningham. 1997. The effects of restraint using self-locking stanchions on dairy cows in relation to behavior, feed intake, physiological parameters, health, and milk yield. J. Dairy Sci. 80:24112417. https://doi.org/10.3168/jds.S0022-0302(97)76193-9.

Cabrera, V. E., J. A. Barrientos-Blanco, H. Delgado, and L. FadulPacheco. 2020. Symposium review: Real-time continuous decision making using big data on dairy farms. J. Dairy Sci. 103:3856-3866.

Cabrera, V. E., F. Contreras, R. D. Shaver, and L. Armentano. 2012 Grouping strategies for feeding lactating dairy cattle. Pages 13-14 in Proc. Four-State Dairy Nutrition and Management Conference. Wisconsin Agri-business Association.

Cabrera, V. E., and A. S. Kalantari. 2016. Economics of production efficiency: Nutritional grouping of the lactating cow. J. Dairy Sci. 99:825-841. https://doi.org/10.3168/jds.2015-9846.

Cerosaletti, P., and D. Dewing. 2008. What is precision feed management? Pages $15-16$ in Proc. Northeast Dairy Producers. ProDairy, Cornell CALS.

Chase, L. 2018. Precision feed management-What have we learned? Pages 1-7 in Proc. Cornell Nutrition Conference. Cornell University.

Clark, P., R. Ricketts, and G. Krause. 1977. Effect on milk yield of moving cows from group to group. J. Dairy Sci. 60:769-772.

Contreras-Govea, F. E., V. E. Cabrera, L. E. Armentano, R. D. Shaver, P. M. Crump, D. K. Beede, and M. J. VandeHaar. 2015. Constraints for nutritional grouping in Wisconsin and Michigan dairy farms. J. Dairy Sci. 98:1336-1344. https://doi.org/10.3168/ jds.2014-8368.

Dickson, D. P., G. R. Barr, L. P. Johnson, and D. A. Wieckert. 1970. Social dominance and temperament of Holstein cows. J. Dairy Sci. 53:904-907. https://doi.org/10.3168/jds.S0022-0302(70)86316-0.

Forgey, E. 1965. Cluster analysis of multivariate data: Efficiency vs. interpretability of classification. Biometrics 21:768-769.

Grant, R. J., and J. L. Albright. 1995. Feeding behavior and management factors during the transition period in dairy cattle. J. Anim. Sci. 73:2791-2803. https://doi.org/10.2527/1995.7392791x.

Grant, R. J., and J. L. Albright. 2001. Effect of animal grouping on feeding behavior and intake of dairy cattle. J. Dairy Sci. 84(E Suppl):E156-E163. https://doi.org/10.3168/jds.S0022 -0302(01)70210-X.

Hernandez-Urdaneta, A., C. Coppock, R. McDowell, D. Gianola, and N. Smith. 1976. Changes in forage-concentrate ratio of complete feeds for dairy cows. J. Dairy Sci. 59:695-707. https://doi.org/10 .3168/jds.S0022-0302(76)84260-9.

Kalantari, A. S., L. E. Armentano, R. D. Shaver, and V. E. Cabrera. 2016. Economic impact of nutritional grouping in dairy herds. J. Dairy Sci. 99:1672-1692. https://doi.org/10.3168/jds.2015-9810.

Kertz, A. F., L. F. Reutzel, and G. M. Thomson. 1991. Dry matter intake from parturition to midlactation. J. Dairy Sci. 74:2290-2295. https://doi.org/10.3168/jds.S0022-0302(91)78401-4.

Liang, D., H. Delgado, and V. E. Cabrera. 2018. A Virtual Dairy Farm Brain. Pages 1-19 in Proc. 13th European IFSA Symposium. International Farming Systems Association (IFSA).

Maltz, E., L. Barbosa, P. Bueno, L. Scagion, K. Kaniyamattam, L. Greco, A. De Vries, and J. Santos. 2013. Effect of feeding according to energy balance on performance, nutrient excretion, and feeding behavior of early lactation dairy cows. J. Dairy Sci. 96:5249-5266. https://doi.org/10.3168/jds.2013-6549.

McGilliard, M. L., J. M. Swisher, and R. E. James. 1983. Grouping lactating cows by nutritional-requirements for feeding. J. Dairy Sci. 66:1084-1093. https://doi.org/10.3168/jds.S0022-0302(83)81905 -5 .

Meijer, R., and K. Peeters. 2010. The use of precision dairy farming in feeding and nutrition. Pages 20-23 in Proc. of the First North American Conference on Precision Dairy Management.

Moorby, J. M., R. J. Dewhurst, R. T. Evans, and J. Danelón. 2006. Effects of dairy cow diet forage proportion on duodenal nutrient supply and urinary purine derivative excretion. J. Dairy Sci. 89:35523562. https://doi.org/10.3168/jds.S0022-0302(06)72395-5. 
Okine, E., G. Khorasani, and J. Kennelly. 1997. Effects of source of forage and level of concentrate on chewing activity and milk production response in late lactation cows. Can. J. Anim. Sci. 77:253258. https://doi.org/10.4141/A96-091.

Olofsson, J. 1999. Competition for total mixed diets fed for ad libitum intake using one or four cows per feeding station. J. Dairy Sci. 82:69-79. https://doi.org/10.3168/jds.S0022-0302(99)75210-0.

Smith, N. E., G. R. Ufford, C. E. Coppock, and W. G. Merrill. 1978. One group versus two group system for lactating cows fed complete rations. J. Dairy Sci. 61:1138-1145. https://doi.org/10.3168/ jds.S0022-0302(78)83697-2.

Sniffen, C. J. 1991. Grouping management and physical facilities. Vet. Clin. North Am. Food Anim. Pract. 7:465-471. https://doi.org/10 .1016/S0749-0720(15)30793-3.

Spilke, J., and R. Fahr. 2003. Decision support under the conditions of automatic milking systems using mixed linear models as part of a precision dairy farming concept. Pages 5-9 in Proc. EFITA 2003 Conference, Debrecen, Hungary.

St-Pierre, N. R., and C. S. Thraen. 1999. Animal grouping strategies, sources of variation, and economic factors affecting nutrient balance on dairy farms. J. Anim. Sci. 77(suppl_2):72-83. https://doi .org/10.2527/1999.77suppl_272x.

St-Pierre, N. R., and W. P. Weiss. 2015. Partitioning variation in nutrient composition data of common feeds and mixed diets on commercial dairy farms. J. Dairy Sci. 98:5004-5015. https://doi .org/10.3168/jds.2015-9431.
Stallings, C. C., and M. L. McGilliard. 1984. Lead factors for total mixed ration formulation. J. Dairy Sci. 67:902-907. https://doi .org/10.3168/jds.S0022-0302(84)81386-7.

White, R. R., and J. L. Capper. 2014. Precision diet formulation to improve performance and profitability across various climates: Modeling the implications of increasing the formulation frequency of dairy cattle diets. J. Dairy Sci. 97:1563-1577. https://doi.org/ 10.3168/jds.2013-6859.

Williams, C. B., and P. A. Oltenacu. 1992. Evaluation of criteria used to group lactating cows using a dairy production-model. J. Dairy Sci. 75:155-160. https://doi.org/10.3168/jds.S0022-0302(92)77749 -2 .

Wu, Y., D. Liang, R. D. Shaver, and V. E. Cabrera. 2019. An income over feed cost nutritional grouping strategy. J. Dairy Sci 102:4682-4693. https://doi.org/10.3168/jds.2018-15302.

Zwald, A., and R. Shaver. 2012. Case study: Effect of pen change on milk yield by dairy cows in 2 commercial herds. Appl. Anim. Sci. 28:569-572. https://doi.org/10.15232/S1080-7446(15)30407-1.

\section{ORCIDS}

Jorge A. Barrientos-Blanco @ https://orcid.org/0000-0003-4788-3050

Heather White ๑ https://orcid.org/0000-0001-5449-2811

Victor E. Cabrera @ https://orcid.org/0000-0003-1739-7457 